\title{
Facade Design and Engineering - Finding the scope within a growing community
}

Facade Design and Engineering in many cases is related to other fields such as structural design, material technology, design and construction processes, building physics and climate design. In the past, research efforts in the field of building envelopes were directed towards those fields, more or less already established in the scientific world. We started JFDE because we felt a specialised journal was needed to react to a constantly growing interest in the discipline and with it, naturally a growing community of readers and authors.

There is evidence of this development in different areas:

Because of rising requirements in terms of energy savings of buildings and more complex constructions, facade design and engineering is becoming a recognised and strong field in building practice. Internationally, there are no longer large projects that do not involve facade specialists. Most large building engineering offices have specialised facade teams, which was not the case a couple of years ago. But the number of specialist offices grows steadily as well.

In parallel, universities worldwide start to create chairs or working groups that focus on the building envelope. The Building Technology master track at TU Delft started a program for Facade Design in 2007. The program is closely linked to the work of the Facade Research Group. We can proudly say that, despite the ongoing recession on the architectural market, our graduates find jobs easily, within the Netherlands and many of them in offices and companies all over the world. We are actively creating our own reader group with young professionals that leave our educational institutions towards practice and research.

Still, there is the question how Facade Design and Engineering will win recognition in its scientific environment. The 'if' is not a question any more!

Our last special issue focussed on glass, and again this issue features two papers about the topic. One is about structural silicone glazing and the other is an applied practice paper about the novel use of glass bricks for a facade in Amsterdam. In our point of view we will see a specialist journal on architectural glass emerging soon. The other papers discuss design tools, constructive strategies for 'massive' envelopes and the assessment of building integrated photovoltaic.

The scope of JFDE is still very broad, and for now we will keep it that way. Research efforts always focus on gaining new knowledge and ultimately aim at improving the built environment. The design of building envelopes is a multifaceted and integrated task. Our target is to bring together the scientific facade community. We will keep observing new trends in research and subsequently determine whether JFDE will need a narrower scope. 
Facade Design and Engineering is a peer reviewed, open access journal, funded by The Netherlands Organisation for Scientific Research NWO (www.nwo.nl). We see 'open access' as the future publishing model. But it certainly requires new financial models which we will have to explore over the coming years.

The editors in chief, Tillmann Klein and Ulrich Knaack 